Análisis del perfil de las cadenas productivas del café, el cacao, la pitahaya y el limón Tahití, desde un enfoque de internacionalización, innovación y responsabilidad social empresarial en Bucaramanga

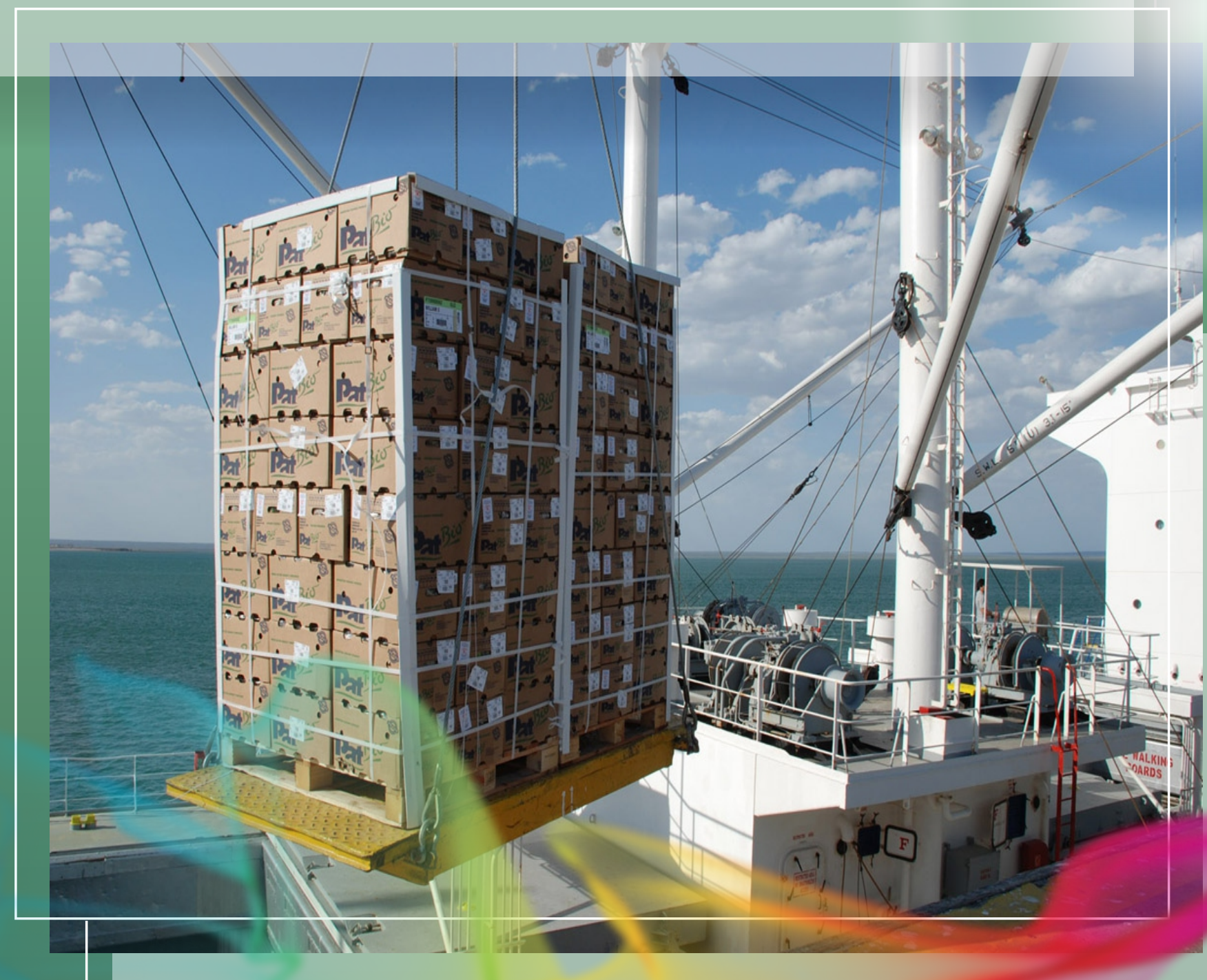




\title{
Análisis del perfil de las cadenas productivas del café, el cacao, la pitahaya y el limón Tahití, desde un enfoque de internacionalización, innovación y responsabilidad social empresarial en Bucaramanga ${ }^{1}$.
}

Coffee, cocoa, tahiti lemon and pitahaya productive chain profiles using an internationalization and innovative perspective as well as a corporate social responsibility in Bucaramanga.

\author{
Maryi Yurany Olarte Dueñas². \\ 'Alcaldía de Bucaramanga, Colombia.
}

Artículo recibido en junio de 2015; artículo aceptado en agosto de 2015.

Citación del artículo: Olarte, M. 2015. Análisis del perfil de las cadenas productivas del café, el cacao, la pitahaya y los cítricos desde un enfoque de internacionalización, innovación y responsabilidad social empresarial en Bucaramanga. I+D Revista de Investigaciones, 6(2), 76-99.

\section{Resumen}

El proyecto tuvo como objetivo evaluar el estado actual de las cadenas productivas del café, cacao, pitahaya y cítricos en el municipio de Bucaramanga, desde los enfoques de internacionalización, innovación y responsabilidad social empresarial, teniendo en cuenta que son factores prioritarios para fortalecer la productividad y competitividad de cualquier gremio y/o sector empresarial o económico de un ente territorial. Para su desarrollo se realizó un grupo focal con productores de los tres corregimientos del municipio a través de la aplicación de un cuestionario mediante la técnica de muestreo, identificando el nivel de acercamiento de los productores con el sector público, agremiaciones y conocimiento e implementación de técnicas de innovación, responsabilidad social empresarial e internacionalización en sus procesos productivos, identificándose el desconocimiento de éstas áreas por parte de los agricultores y/o dueños de las fincas, puesto que dependen en un alto porcentaje de las federaciones y demás entidades que les representan.

${ }^{1}$ Artículo de investigación de tipo cuantitativo, resultado de un proyecto de investigación trabajado en conjunto con la Alcaldía de Bucaramanga y el semillero Maslow del Grupo Porter de la Universitaria de Investigación y Desarrollo (UDI). Calle 9 No. 23-55, PBX: 6352525, ext. 104. Fecha de inicio: enero de 2015, fecha de terminación: junio de 2015.

${ }^{2}$ Economista, Universidad Industrial de Santander. Magíster en Administración, Universidad Santo Tomás de Aquino, asesora de la Secretaría de Desarrollo Social en Políticas Públicas. Dirección: Carrera 11 No. 34-52, PBX: 6337000. Correo electrónico institucional:molarte1@udi.edu.co. 
El estudio permitió concluir la necesidad de establecer estrategias de comunicación asertiva entre entidades del sector público y los productores del sector rural del municipio, asistencias técnicas de largo plazo en formación e implementación de procesos basados en innovación, internacionalización y responsabilidad social empresarial, tanto de forma directa como a través de intermediarios organizados. Así, el aporte del proyecto se basó en la identificación de las falencias y oportunidades del sector agroindustrial, específicamente en los productos objeto del estudio.

Palabras clave: responsabilidad social, agroindustria, innovación tecnológica, comercio internacional, productividad.

\section{Abstract}

The project aimed to assess the current state of the production chains of coffee, cocoa, citrus pitahaya and in the city of Bucaramanga from the approaches of internationalization, innovation and corporate social responsibility, taking into account factors that are priorities for strengthening productivity competitiveness of any guild and / or business or economic sector of a local authority. For its development a focus group was held with producers in the three districts of the municipality through the application of a questionnaire by the sampling technique, identifying the zoom level of the producers with the public sector, guilds and technical knowledge and implementation Innovation and Internationalization Corporate Social Responsibility in their production processes, identifying the ignorance of these areas by farmers, since they depend on a high percentage of the Federations and other entities that represent them. This study showed the importance of assertive communication strategies between public sector entities and producers in the rural sector of the municipality, long-term technical training and implementation based on innovation, internationalization and corporate social responsibility processes both directly assists organized as through intermediaries. So the contribution of the project was based on the identification of gaps and opportunities in agribusiness products specifically surveyed.

Keywords: social responsibility, agroindustry, technological innovation, international trade, productivity.

\section{Introducción}

La globalización y los procesos de industrialización han requerido que las economías se dinamicen a través de sus unidades productivas, desarrollando procesos de innovación, responsabilidad social empresarial e internacionalización para generar mayores niveles de productividad y competitividad, resaltando así los avances que les son reconocidos a los territorios, principalmente los urbanos, contextualizados desde un enfoque de crecimiento y desarrollo económico.

En este sentido es primordial mencionar que el municipio de Bucaramanga ha sido considerado como un centro de acopio agrícola y artesanal de los municipios vecinos, puesto que ha sido reconocido por su comercialización con 
municipios aledaños, con los cuales se comerciaba café, sombreros, ganado, tabaco, cacao, oro, panela, maíz, arroz, objetos textiles de mimbre, fique, alfarería, café y harinas (Rueda, 2003).

Actualmente, mediante el Plan de Ordenamiento Territorial (POT) se tienen concebidos tres corregimientos en el municipio de Bucaramanga, donde se produce café, cacao, pitahaya y cítricos, productos objeto de estudio del presente análisis. Es por esto la importancia de resaltar que el estudio ha priorizado al sector agrícola ya que la agricultura y el desarrollo rural han sido considerados como una de las cinco locomotoras de crecimiento de la economía del país y han sido incluidos en el Plan Nacional de Desarrollo 2010-2014 "Prosperidad para todos", calificando al agro como una futura despensa productiva mundial e identificado históricamente como un sector estratégico para el País por su contribución al Producto Interno Bruto ( PIB), a la generación de empleo, y la presencia en el extenso territorio nacional, sin embargo; según la Corporación para el Desarrollo de las microempresas PROPAIS, el país y las entidades prestadoras de servicio de desarrollo empresarial, deben enfrentar el desafío de la ausencia de Competitividad y Productividad debido al uso inadecuado de los factores de producción y la baja innovación en los procesos de producción (PROPAIS, 2011,p4).

\section{Descripción del problema}

Si bien el sector agropecuario es considerado como uno de los más importantes del país, se cree que tendrá un futuro promisorio y goza de gran reconocimiento por los aportes realizados a la economía en el transcurrir de la historia, sin embargo, no debe soslayarse que se ha identificado que el sector debe realizar transformaciones que le permitan ser más productivo, innovador y competitivo (Uribe, Fonseca, Bernal Contreras \& Castellano, 2011).

Sujetándose además a que desde hace cuarenta y cinco años no se realizaban censos en el sector que permitieran identificar los factores que limitan su crecimiento y desarrollo, en el año 2013 se ordenó al Departamento Nacional de Estadísticas DANE la realización de dicho censo. Se encontró que no existen bases de datos que permitan unificar datos estadísticos frente a la temática para el país, pues no se cuenta con estadísticas continuas, oportunas, consistentes y confiables, ni con series que permitan construir un modelo integrado para la producción y oferta de estadísticas del sector, lo que limita los procesos de planificación y toma de decisiones por parte del gobierno (Gutiérrez, sf).

Por tanto, con el fin de iniciar el proceso de actualización de la información básica agropecuaria y rural que permita la formulación de programas y proyectos para el desarrollo económico, social, ambiental e institucional acorde con las ventajas y las oportunidades de cada una de las regiones, se adelantó por parte del DANE la realización del Censo Agropecuario en los departamentos del Magdalena, Córdoba y Antioquia entre otros, incluyéndose el Departamento de Santander para fechas posteriores.

Cabe apuntar, sin embargo, que pese a los esfuerzos del orden nacional para garantizar la oferta de estadísticas del Sector Agropecuario, el Censo realizado por el DANE no contempla 
indicadores específicos para unificar datos relacionados con las características generales del sector, tamaño de las fincas, producción, cultivo, procesos de internacionalización, innovación y responsabilidad social empresarial, que son el pilar de análisis del presente artículo, lo que hace relevante el estudio puesto que es información fundamental para diagnosticar el estado de la productividad y competitividad de las fincas del municipio de Bucaramanga.

\section{Planteamiento del problema}

Para efectos de la investigación y con el fin de construir herramientas suficientes para la planificación y toma de decisiones por parte del gobierno departamental y municipal en cuanto a la producción y comercialización de los productos objeto del proyecto en el ente territorial $\mathrm{y}$, con el fin de fortalecer a los productores y comercializadores de café, cacao, pitahaya y cítricos en el municipio de Bucaramanga, es relevante identificar sí los dueños de fincas y productores ubicados en los tres corregimientos de Bucaramanga, han incorporado en sus procesos de producción y comercialización:

\section{Innovación tecnológica}

2. Comercio internacional o internacionalizacióny

3. Responsabilidad social, ya que son bases fundamentales para la productividad $y$ competitividad de la agroindustria.

Surgiendo el siguiente interrogante: ¿cómo se han desarrollado los procesos de innovación, internacionalización y responsabilidad social empresarial en el sector agropecuario específicamente en cítricos, pitahaya, café y cacao en el municipio de Bucaramanga?

\section{Justificación}

Algunos de los aspectos que hacen prioritario los análisis del sector agropecuario y sus productos son: 1) el sector agropecuario se ha considerado como la segunda locomotora de la economía del país; 2) para crecer en mercados competitivos y globalizados se requiere ser productivos, incluir innovación en los procesos de producción y comercialización, comercializar los productos en el exterior, y actuar bajo los principios de la responsabilidad social empresarial es decir; mantener Buenas Practicas Agrícolas (BPA), Buenas Prácticas Laborales (BPL), Compromiso ambiental, calidad y la no utilización de mano de obra infantil 3) ausencia de trabajos de investigación que permitan identificar las problemáticas más importantes; 4) El café, el cacao, los cítricos y la pitahaya son los productos promisorios del sector rural de Bucaramanga, de acuerdo con el director de la Umata de Bucaramanga, el doctor Javier Armando Quiroga.

Por otro lado, cabe resaltar el hecho de que el café ha sido uno de los productos más importantes de la economía colombiana por su contribución en la generación de empleo, no obstante en la actualidad ha estado sujeto a la volatilidad en sus precios causado por fenómenos climáticos, el alza del dólar entre otros factores que requieren atención por parte de las entidades estatales y privadas con el fin de que se generen estrategias y políticas que permitan fortalecer el sector cafetero.

Pero no solo el sector del café que ha sido reconocido como un producto tradicional de Colombia y que ha contribuido con el crecimiento del sector agropecuario del país por 
sus importantes ventas y posicionamiento a nivel internacional, sino también el cacao, la pitahaya y los cítricos, deben estar incluidos dentro de las agendas del gobierno nacional, departamental y local ya que tienen grandes oportunidades para la comercialización y posicionamiento internacional, el cual se logra, según afirma Herrera (2000), mediante el conocimiento y la capacidad de innovación, para optimizar los costos y sus capacidades de innovación productiva(FAO. Fiat Panis, 2012).

\section{Objetivos}

La investigación se basa en el análisis de la producción y comercialización de café, cacao, pitahaya y cítricos en el municipio de Bucaramanga desde el contexto de la innovación y la comercialización al exterior, con el fin de producir un informe que permita a los gobernantes, productores y demás entidades que apoyan al sector agropecuario tomar decisiones para fortalecer el sector agrario del ente territorial a partir del apoyo a productores, dueños de fincas y/o unidades empresariales, sujetos a las políticas nacionales que incluyen el sector agrario como una de las locomotoras para el crecimiento del país. Planteando los siguientes objetivos:

\section{Objetivo general}

Analizar las cadenas productivas del café, el cacao, la pitahaya y los cítricos a partir de un enfoque de procesos de internacionalización, innovación y responsabilidad social de las fincas del sector rural del Municipio de Bucaramanga.

\section{Objetivos específicos}

1) Analizar la producción y comercialización de cítricos, café, cacao y pitahaya a nivel nacional y departamental. 2) Identificar la aplicación de procesos de internacionalización, innovación y responsabilidad social empresarial en Bucaramanga en la producción y comercialización de café, cacao, Pitahaya y cítricos. 3) Realizar la primera fase de un informe técnico basado en el diagnóstico de las variables de internacionalización, innovación y responsabilidad social empresarial, que sirva de base para entidades de orden estatal y privada para la toma de decisiones y planteamiento de estrategias.

\section{Marco teórico-estado del arte}

Diversas han sido las concepciones que se les han dado a la competitividad, iniciando con el enfoque dado al término en la CEPAL durante los años 90, introducido por Fajnzylber F (1988), quien determinó que la única manera de ganar la competitividad auténtica es incrementando la productividad y el progreso técnico, entendida la productividad como: "La medida de la eficiencia económica que resulta de la relación entre los recursos utilizados y la cantidad de productos o servicios elaborados", lográndose la eficiencia según la teoría económica mediante el consumo, la satisfacción del consumidor y la producción (Santos, 2004).

Como una segunda teoría de competitividad se encuentra la dada por lo que se conoce en la literatura como el Diamante de Porter, procedente de la vertiente macroeconómica de la organización industrial y de la estrategia empresarial, formulado a partir de una investigación empírica exhaustiva en diez países de alto dinamismo en el comercio internacional y con un marco interdisciplinario, identificándose cuatro grandes determinantes: 1) condiciones de 
los factores de producción básicos y avanzados; 2) condiciones de demanda: tamaño del mercado interno; 3) industrias relacionadas o de apoyo: empresas proveedoras usuarias, internacionalmente competitivas; 4) estrategias de las empresas y marco regulatorio de la competencia interna(Moncayo, 2004).

Otra definición de competitividad es la denominada competitividad sistémica, que se vale de un polígono de interacciones presentado por el Instituto Alemán de Desarrollo de la CEPAL con base a los trabajos de la OECD, donde define cuatro niveles importantes: 1) nivel meta, 2) nivel macro 3) nivel meso y 4) nivel micro, partiendo desde las estructuras básicas de organización jurídica, política económica y social, mercados eficientes, políticas de apoyo y articulación de procesos de aprendizaje así como la búsqueda simultánea de eficiencia, calidad, flexibilidad y rapidez de reacción en redes de colaboración de cadenas mutuas (Moncayo, 2004).

La competitividad trae así controversias en cuanto a su uso para el crecimiento y desarrollo económico, puesto que existen críticas al uso e importancia que se le da a la competitividad, como las que hace Krugman, Paul (1994) quien afirma que "no tiene sentido hablar de competencias entre los países, porque estos no compiten entre sí en la forma en que lo hacen las empresas, ya que el comercio internacional no es un juego de suma cero en donde la ganancia de un actor es la pérdida del otro, sino un intercambio que produce beneficios para ambas partes"; sin embargo, otros autores consideran pertinente una política de competitividad encaminada a corregir deliberadamente las fallas del mercado que "impiden una asignación óptima de los recursos y hace posible un cambio estructural para los sectores de más alta productividad" (Moncayo, 2004). Vale la pena entonces, hacer referencia a que la competitividad se encuentra estrechamente relacionada con la internacionalización, siendo necesario mantener las ventajas competitivas y una continua política de innovación(Márquez, 1998).

Entendiéndose la innovación según lo expuso Santiago Sousa Carrera (2010) en su libro " la actitud innovadora: cinco principios para generar una nueva forma de gestión" en su cita bibliográfica que refiere al economista Shumpiter, quien explica que la innovación es: "Cualquier modo de hacer las cosas de forma distinta en el reino de la vida económica".( Sousa,2010, p.63). Por lo tanto, ejemplos de innovación serían la introducción de un nuevo producto, un nuevo método de producción, la apertura de un nuevo mercado, la utilización de una nueva fuente de aprovisionamiento o la puesta en práctica de una nueva estructura en un mercado. Una segunda definición es la que ofrece el Instituto Nacional de Estadísticas (INE), en su encuesta de Innovación Tecnológica elaborada desde el año 1994, según la cual la innovación se refiere a:

"Un producto (bien o servicio), nuevo o sensiblemente mejorado introducido en el mercado o un proceso nuevo o sensiblemente mejorado introducido en la empresa".( Sanchez,2008).

La innovación se basa en los resultados de nuevos desarrollo tecnológicos, nuevas combinaciones de tecnologías existentes o en la 
utilización de otros conocimientos adquiridos por la empresa.

Así se consideran actividades para la innovación las siguientes (INE, 2005): I+D interna, adquisición de $\mathrm{I}+\mathrm{D}$ externa, adquisición de maquinaria, equipos y hardware o software Avanzados, Adquisición de otros conocimientos externos para Innovación, Formación, introducción de innovaciones en el mercado, diseño, otros preparativos para producción o distribución .(Sánchez, 2008)

Siguiendo el contexto de la competitividad cabe destacar que existe otro parámetro de interés de ésta investigación, la responsabilidad social empresarial (RSE), la cual ha sido abordada por las empresas como una herramienta que permite hacer diferenciación sobre sus competidores, y que es definido por López, Contreras y Molina (2011), en el estudio "La Responsabilidad Social Empresarial como estrategia de Competitividad en el sector alimentario" tomando como referencia, diferentes definiciones como aparecen a continuación:

1. Para (Rodríguez, 2008.p.11), la RSE es "un concepto a través del cual la empresa integra de forma voluntaria las dimensiones social y medioambiental en sus relaciones con los grupos de interés. Lo que implica que las empresas deben tener una visión integral de su negocio donde se respeten las personas, la sociedad y el medio ambiente".

2. Kligsberg (2009)." Manifiesta que a pesar que la Responsabilidad Social Empresarial se vuelva cada vez más compleja es claro que comprende el tema de derechos humanos, gobierno corporativo, prácticas de negocios justas, relaciones con los consumidores, prácticas laborales, medio ambiente, interés en la comunidad, y en el desarrollo.

3. El Business for Social Responsability - BSR (2000) sostiene que la "responsabilidad social empresarial es la administración de un negocio de tal forma que excede las expectativas éticas, legales, comerciales y públicas que tiene la sociedad hacia una empresa".

Vale la pena mencionar que existen otras definiciones de responsabilidad Social Empresarial citadas en otros estudios como: "Competitividad y casos de buenas prácticas en Pequeñas y Medianas empresas Pymes de la universidad de Deusto" (Gilbert, s.f). donde se cita la definición de RSE dada por la Comisión de las Comunidades Europeas en el año 2001 de la siguiente manera "RSE es la integración voluntaria, por parte de las empresas, de las preocupaciones sociales y medioambientales en sus operaciones comerciales y sus relaciones con sus interlocutores".

Por tal razón se debe concebir la responsabilidad social a partir de enfoques macroeconómicos, microeconómicos, costos de transacción, administrativos, Teoría de la regulación, desarrollo sustentable, stakeholders e institucionalidad que permitan atender los intereses de la sociedad.

Considerándose que la responsabilidad social empresarial o corporativa, no tiene una definición única ya que empresarios o stakeholders presentan una visión diferente del concepto desde el punto de vista de los beneficios y los costes que generan para cada actor. 


\section{Metodología propuesta}

Este informe tuvo un alcance descriptivo de la cadena a partir de los enfoques de innovación, internacionalización y responsabilidad social empresarial, obteniendo la información a partir de fuentes secundarias y la selección de un grupo focal que permite el acercamiento a los productores y su acompañamiento por parte de profesionales de la Unidad Técnica de Asistencia Agropecuaria del Municipio de Bucaramanga, Umata. A través de los profesionales de la Umata se identificó que existían aproximadamente 80 fincas productoras de cacao vinculadas a la Federación de Cacaoteros, 80 fincas de café vinculadas a la Federación de Cafeteros, 100 Productores de pitaya y 20 fincas productoras de cítricos, para un total de 280 hectáreas de tierra cultivadas con los productos objeto de este estudio.

Para el análisis realizado a la producción de café, cacao, pitahaya y cítricos en el municipio de Bucaramanga, se tomó una grupo de 52 productores de las fincas de los corregimientos 1 , 2 y 3 del municipio de Bucaramanga, convocados a un grupo focal a través de los profesionales de la Umata y los representantes del sector agrícola en cada corregimiento seleccionada mediante el método de muestras no probabilísticas. Para la recolección de la información se realizó un cuestionario compuesto por seis componentes, evaluados mediante preguntas cerradas modalidad dicotómica (Figura 1).

Figura 1. Componentes de análisis para la evaluación realizada al sector agrícola de Bucaramanga.

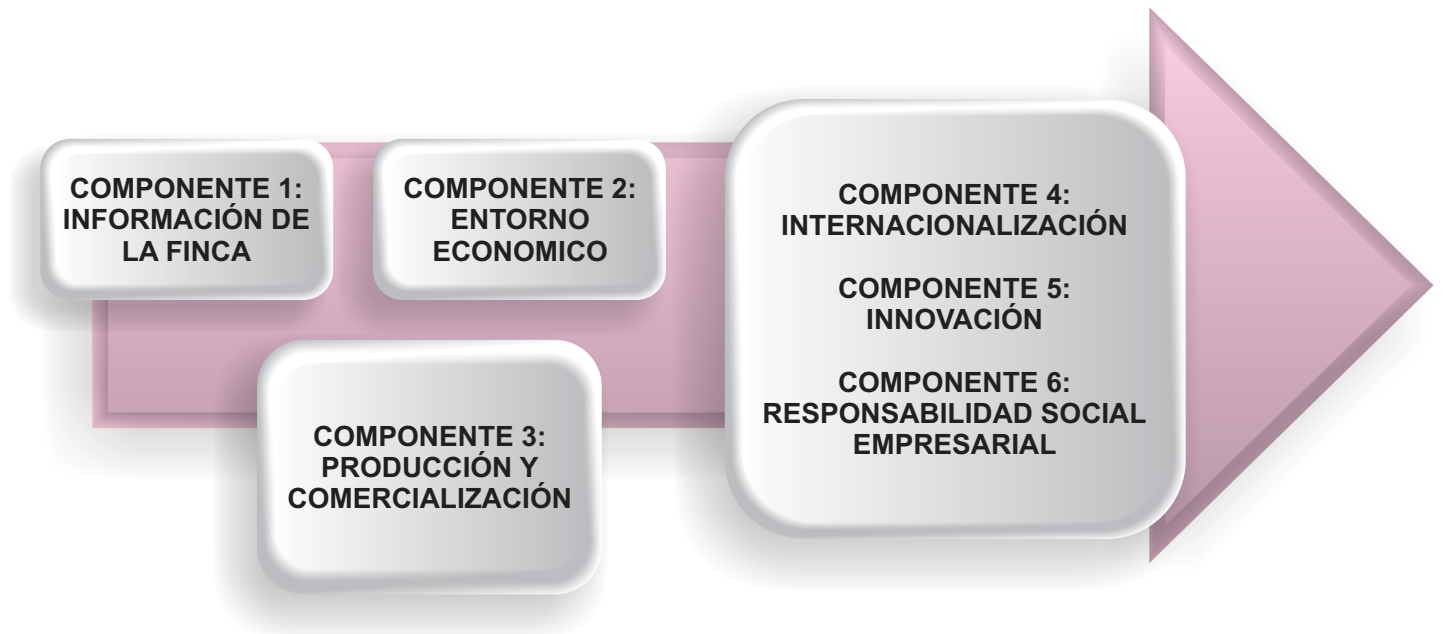

Fuente: La autora.

A continuación se encuentran dos apartados: 1.Contextualización de la producción y comercialización de café, cacao, pitahaya y cítricos a partir de fuentes secundarias y $\mathbf{2}$. Resultados de la aplicación del cuestionario realizado a los productores del sector rural de Bucaramanga.
Revisión de literatura de la Producción y Comercialización de Café, Cacao, Pitahaya y Cítricos en el Contexto Internacional y Local.

\section{Producción y comercialización de café}

Según el Ministerio de Agricultura y Desarrollo Rural y Observatorio de Agro- 
cadenas1991-2005, el Comportamiento de las Cadenas del Café ha demostrado crecimiento negativo de su participación en el mercado Internacional, cediendo espacios a países competidores como Vietnam e Indonesia, incluso a países de Centroamérica y Perú donde escasea el café de grano verde. Concentrándose la producción de cafés procesados o industrializados, en países como Estados Unidos, Alemania, Italia y Bélgica-Luxemburgo posicionadosen en exportación por tener un producto con mayor nivel de elaboración que el exportado por Colombia. (Ministerio de Agricultura y Desarrollo Rural, 2005).

El sector cafetero según estudios realizados por el Programa de las Naciones Unidas (PNUD, p.14) ha presentado baja productividad, ya que en el año 2002 la producción por hectárea de café verde en Colombia era de $980 \mathrm{k} / \mathrm{ha}$, pero 9 años más tarde descendió a $633 \mathrm{k} / \mathrm{ha}$, es decir, un promedio anual de $3.5 \%$, indicando en términos de producción pasar de 694 mil toneladas de café verde en 2002 a 468 mil toneladas en 2011, ocasionando una contracción de la producción en un $33 \%$.

Las anteriores cifras, permiten evidenciar que se afectan otras variables como bien lo menciona el estudio del Programa de Naciones Unidas, las cuales son: las Exportaciones, ingresos, sostenibilidad del sector, e incrementos de los costos de producción, con lo cual se afecta negativamente la competitividad sectorial, mientras países competidores en producción aumentaron su productividad en el mismo periodo como se indica a continuación respectivamente. Brasil en 12\%; Perú y Guatemala en 7,3\%; Honduras 26\% y Vietnam
$54 \%$, agudizando la crisis del sector por la caída del precio.( $\mathrm{PNUD}, \mathrm{Sf}$ ).

Por otro lado vale la pena mencionar que la caída de precio del café y la terminación del acuerdo Internacional del Café ha hecho desde hace algunos años que los países productores tengan que someterse al precio generado por la oferta y la demanda del producto lo cual pone en peligro la dinámica estable de la economía del sector teniendo en cuenta que han aparecido otros productores como Vietnam, ya referenciado en párrafos anteriores que para el año 2006 ya figuraba como un segundo productor a nivel mundial, colocando precios cercanos a los US\$0.25, precios que según Alfonso Ortega Cárdenas (2007) en su libro Economía Colombiana, ni al multiplicarlos por tres cubrirían los costos de la Producción Nacional, habiéndose entonces incrementado el consumo de café del exterior ( Perú, Vietnam y Ecuador), determinado políticas que desde la Federación de Cafeteros se dirige al pago por sustitución de cultivos de café por otro producto por hectáreas.

Sin embargo, es de resaltar que según el informe realizado por Gerente General de la Federación de Cafeteros de Colombia, realizado en el año 2013, "la producción mundial del café creció en un 5\% llegando a una producción total de 146,8 millones de sacos, con una producción en Colombia de 10,9 millones de sacos de café en este mismo año, en el año 2014 la producción ascendió a 12,1 millones y al mes de abril de 2015 se reflejaba una producción de 3,8 millones, incrementándose las exportaciones del café en un 35\% para el año 201"3.(Federación Nacional de cafeteros, 2013, p.12). 
Los principales exportadores del café fueron Brasil con 55 millones de sacos, Vietnam 24 millones de sacos, Indonesia 11 millones y Colombia 10 millones, creciendo con respecto del año inmediatamente anterior en aproximadamente 3,1 millones de sacos, resultado del programa de renovación de cafetales emprendido por los cafeteros con el apoyo de la federación de cafeteros nacional, cuyo objetivo es elevar la productividad y mejorar la sanidad vegetal de los cafetales ya que contar con cafetales más jóvenes permite enfrentar el desafío del cambio climático que actualmente se vive a nivel mundial. Debido a lo anterior la productividad por hectárea aumentó pasando en 2012 de 11,1 sacos de café verde por hectárea a 14 sacos en el año 2013, generando una reducción en la importación del café en un $30 \%$ el cual pasó de 1,1 millones de sacos de 60 $\mathrm{kg}$ en 2012 a 600 mil en el año 2013, según el informe realizado por el gerente de la federación de cafeteros en el año 2013. (Federación Nacional de Cafeteros, 2013).

Igualmente es importante mencionar en este apartado que la volatilidad de los precios internacionales del café, efecto del incremento en la producción del grano de café, ha generado una gran coyuntura en el sector, que hace necesario implementar innovación en la producción y comercialización del grano del café, con el fin de cosechar café de alta gama en calidad que cree ventajas comparativas y competitivas en el mercado internacional y así fortalecer el posicionamiento de marca del café Colombiano.
La Oportunidades del sector cafetero a nivel internacional se encuentran en la ampliación de mercados en América y Europa, siendo los aliados más importantes Estados Unidos, Canadá y Argentina con variedad de productos de café verde, verde descafeinado, tostado en grano, tostado y molido, extracto y soluble. También exportando Colombia Café a Japón, Corea del Sur, Australia y otros.

\section{Producción y comercialización de cacao}

En el sector agropecuario la producción y comercialización de cacao ha cobrado gran importancia, mostrando un comportamiento favorable para la economía en el orden nacional y con grandes oportunidades a nivel internacional. Es un producto que requiere mano de obra intensiva lo que permite ser un sector generador de empleo. Colombia se constituye como un país productor y consumidor, con un valor agregado importante, representado por empresas que transforman el producto con estándares de calidad y tecnología de punta. Considerándose a Santander como el primer productor de cacao en el país (Mojica y Paredes, 2006).

Representando el departamento una producción total del país entre el 39\% y 50\% durante el periodo anual comprendido entre 2002 y el año 2014. (Ver tabla 1). Lo que permite evidenciar la importancia de generar políticas de parte del gobierno departamental y local para fortalecer este sector y promover la economía de la región mediante el sector agrario, mejorando sus grados de tecnificación de los procesos de producción, recolección, poda y comercialización. 
Tabla 1. Producción Nacional en toneladas anuales de cacao en el periodo 2002-2014.

\begin{tabular}{lrrrrrrrrrrrrr}
\hline \multicolumn{1}{c}{ AÑO } & $\mathbf{2 0 0 2}$ & $\mathbf{2 0 0 3}$ & $\mathbf{2 0 0 4}$ & $\mathbf{2 0 0 5}$ & $\mathbf{2 0 0 6}$ & $\mathbf{2 0 0 7}$ & $\mathbf{2 0 0 8}$ & $\mathbf{2 0 0 9}$ & $\mathbf{2 0 1 0}$ & $\mathbf{2 0 1 1}$ & $\mathbf{2 0 1 2}$ & $\mathbf{2 0 1 3}$ & $\mathbf{2 0 1 4}$ \\
\hline S/der & 16280 & 19719 & 16803 & 17.974 & 15017 & 16723 & 18178 & 17272 & 19411 & 16165 & 16225 & 19517 & 19085 \\
& & & & & & & & & & & & & \\
Colombia & 34002 & 41704 & 36356 & 37099 & 30357 & 33482 & 37718 & 36118 & 42294 & 37203 & 41670 & 46739 & 47732 \\
\% Santander & 48 & 47 & 46 & 48 & 49 & 50 & 48 & 48 & 46 & 43 & 39 & 42 & 40 \\
\hline
\end{tabular}

Fuente: Elaborado por el autor en base a datos tomados informe Fedecacao recuperado en: http://www.fedecacao.com.co/site/index.php/1eco-economia/2eco-nacionales

Según la Federación Nacional de Cacaoteros, a nivel internacional los países: Costa de Marfil, Ghana, Nigeria, Camerún y otros países de África fueron los mayores productores de cacao; por el lado de América son productores Brasil, Ecuador, República Dominicana, Perú, Colombia, México, Venezuela y otros países; también se incluyen Indonesia, Nueva Guinea, Malasia e India, entre otros, y con la menor producción mundial Asia y Oceanía. Manteniéndose comportamientos en crecimiento para el periodo 2010-2014, siendo Costa de Marfil el mayor productor de cacao. Lo que permite analizar que si Colombia transforma su producción con valor agregado mediante la industrialización y transformación de productos, se pueden abrir oportunidades en la exportación hacia los países de Asia que presentan la menor producción, una vez sea investigado el mercado y revisado la demanda potencial de los productos de café mejorados y diferenciados .

Igualmente el departamento tiene un futuro promisorio debido a los numerosos Tratados de libre Comercio que permiten realizar ventas a países como Pensylvania, Nueva York, California, Illions y Nueva Jersey, Bélgica,
Países Bajos, Francia, Reino Unido, Alemania e Italia.

\section{Producción y comercialización de pitahaya}

Colombia en el mercado internacional se ha caracterizado por la producción y comercialización de la Pitahaya amarilla exportada inicialmente a Japón y Europa, Sin embargo, debido a la presencia de larvas en la fruta, Japón decide cerrar las negociaciones de comercialización de la fruta con Colombia. (Delgado, 2010). Lo que evidencia la dificultad para producir en el país con estándares de calidad que permitan expandir a mercados internacionales las producciones agrícolas. Es por situaciones como ésta que se puede concluir que es necesario implementar procesos de innovación tanto en la producción como en la comercialización en el sector agrícola con el fin de generar ventajas competitivas y aprovechar el potencial que brinda la geografía Colombiana.

Sin embargo para el año 2010 representantes de la División de Corporación Internacional de Cuarentena de Corea, evaluaron las condiciones fitosanitarias de cultivos de Pitahaya Amarilla en Valle del Cauca y Risaralda con resultados 
satisfactorios, lo que abrió las posibilidades de importación desde corea de la fruta colombiana. (ICA, 2010).

Según el documento Portafolio "Sembramos a Colombia por el mundo“ de la revista Modelo. (2013), Donde se cita a la Encuesta Nacional Agropecuaria (ENA) que arrojó que en el año 2007 “el cultivo de Pitahaya presentó un crecimiento en las variables: área plantada de $2 \%$, área cosechada $21 \%$ y producción $29 \%$ como reflejo de los altos precios del producto en el mercado generándose una sobreoferta, y que como efecto de este comportamiento los precios posteriormente tienden a la baja. Para el año 2009 la misma Encuesta ENA, presenta 470 hectáreas plantadas de Pitahaya Amarilla, con un total de 947 toneladas producidas, de las cuales el 37\% fue producida en Santander ocupando el primer lugar entre los departamentos productores, seguida por Boyacá con el 34\% de la producción total, Huila en un tercer lugar con un porcentaje del $10 \%$ de la producción y seguida por Cundinamarca (8\%), Valle del Cauca (7\%) y otros departamentos no referenciados en el estudio (4\%) (Revista Modelo, Portafolio,2013), Cifras de las cuales se puede deducir el potencial que tiene el Departamento de Santander en la producción Pitahaya Amarilla con aceptación internacional.

Según este mismo artículo, Pedro Aguilar, experto del sector Frutícola Internacional, afirma que en el mercado internacional los únicos proveedores de pitahaya amarilla a nivel mundial son Colombia, Ecuador e Israel, y recientemente Filipinas, encontrándose todos estos países compitiendo con Colombia por el mercado japonés.(Revista Modelo, 2013).
Por tanto vale la pena mencionar que los principales países de exportación son los que pertenecen al mercado Europeo, y considerándose según Asopitahaya que Colombia le vende a exportadores que la comercializan en países como Holanda, Italia y España (Revista Modelo, 2013). También se exporta a otros países como Alemania, Brasil, y Canadá e inclusive a Hong Kong y Japón (Revista Modelo, 2013).

\section{Producción y comercialización de cítricos}

Aunque Colombia es un país con las condiciones climáticas y geográficas para la producción de Cítricos y con oportunidades en el mercado internacional, a nivel mundial y en comparación con otros países se ha considerado como un actor marginal en lo que respecta a la producción del sector Citrícola.(Aguilar, Escobar \&passaro,2012).

Sin embargo, lo descrito en el párrafo anterior no debe ser un obstáculo para que los gobiernos nacionales, departamentales y locales se interesen por el sector puesto que en los últimos años, ha tenido una participación importante en cuanto a las áreas de producción sembrada de naranjas, limones, limas, mandarinas, y toronjas, frutas que son transformadas en jugos, néctares, purés, pastas, pulpas, jaleas, mermelada, aceites, esencias y pellets para alimentación animal (Aguilar, Escobar \&passaro,2012) después de un proceso industrializado, evidenciándose una variedad importante de productos derivados del sector citrícola que puede ser aprovechada para la comercialización internacional, y así dinamizar el sector agrícola y la economía nacional.

Colombia presentó un dinamismo importante 
en crecimiento para el periodo $1992-2003$ con un crecimiento promedio anual de $6,8 \%$ en el volumen de producción y de $7.0 \%$ en la superficie de cultivo, siendo superior al crecimiento que registra el sector frutícola total. Los cítricos en 1992 constituían $22.9 \%$ del total de hectáreas sembradas y para el 2003 participaron con un $30.2 \%$. La producción se concentra en los departamentos de Santander, Norte de Santander, Boyacá, Cundinamarca, Tolima y Huila, cubriendo en conjunto más del $50 \%$ de la producción nacional. Las exportaciones se concentran en un $47 \%$ hacia Ecuador, Siguiéndole Estados Unidos con $16,8 \%$, Holanda con 12,5\% y zona Franca del Pacifico 5.4\%.(Espinal G.2005)

Con respecto al Departamento de Santander según los cálculos del Plan Frutícola de Santander (Ministerio de Agricultura y Desarrollo Rural, Gobernación de Santander, Fondo Nacional de Fomento Hortofrutícola, Asohofrucol \&Sociedad de Agricultores y Ganaderos del Valle, 2006) para los años 20052010 se mantienen consumos importantes de limón y naranjas, frutos del sector citrícola, con un crecimiento permanente en el consumo de limón que va desde 8187 toneladas anuales para el año 2005 y un alcance a 2010 de 8893 toneladas anuales y un numero de toneladas superior para el caso de las naranjas con un consumo para el año 2005 de 32.563 toneladas anuales y al 2010 un consumo total de 35.370 toneladas anuales. Tomando el consumo de naranjas el primer lugar dentro del consumo de fruta fresca en el departamento de Santander seguida por el consumo de banano con un promedio de consumo de 13.691 toneladas anuales para el 2005 y un consumo de 14.871 toneladas anuales para el año 2010 y en un tercer lugar el consumo de limón con las toneladas que se enunciaron anteriormente, lo que permite concluir que a nivel del departamento el sector citrícola presenta comportamientos favorables para la comercialización doméstica beneficiando a los productores del municipio de Bucaramanga que están iniciando sus unidades empresariales en el sector.

En el mismo estudio del Plan Frutícola de Santander (Ministerio de Agricultura et al. 2006) se identifican como necesidades de investigación para el sector Citrícola ( Mandarina, Naranja y lima Tahití), "la evaluación de nuevos patrones, identificación y manejo de los ácaros, Manejo de la Botrytis y Alternaria, evaluación de sistemas de riesgos, y adaptación de nuevas variedades mejoradas y evaluación de cadenas de frio para frutas de exportación", lo que permite deducir que el gobierno, la academia y asociaciones de productores de cítricos si existieran, deberían haber realizado proyectos de investigación enfocados hacia estas necesidades.

Agronet identifica que entre los factores que limitan la competitividad del sector de Cítricos para Colombia y que por tanto limita las oportunidades para la internacionalización son: la falta de escalas comerciales significativas, la alta dispersión geográfica de la producción, la falta de gestión empresarial y de desarrollo tecnológico, el bajo grado de asociatividad entre los productores, la falta de investigación y transferencias de tecnologías (desarrollo de variedades y calidades), la presencia de plagas y enfermedades de los cultivos.

El sector de Cítricos en Colombia, además se 
visualiza como un sector potencial ya que aporta a la generación de empleo; estimando que en el año 2000 aproximadamente generó 37000 empleos, de los cuales 30000 eran directos y 7000 indirectos, los cuales se relacionaban con comercializadores, intermediarios, plazas mayoritarias y minoristas, mercados especializados y mercados mundiales (Espinal, 2005).

\section{Resultados del grupo focal}

En este capítulo se tiene como objetivo mostrar los resultados del análisis que se realizó a las cadenas productivas de Café, Cacao, Pitahaya y Cítricos en el municipio de Bucaramanga en los aspectos de Producción, Internacionalización, Innovación y Responsabilidad Social Empresarial. Para esto es importante precisar que se aplicó un cuestionario a 53 dueños de fincas del municipio de Bucaramanga convocados a través de los profesionales de la Unidad Técnica de Asistencia Agropecuaria del Municipio, Comité de Cafeteros, y representantes de las asociaciones de cada uno de los Productos (Café, Cítricos en el municipio.

Como resultado del grupo focal se pudo notar que no hay especialización para la producción, ya que la mayoría de los dueños de las fincas de los Corregimientos del municipio de Bucaramanga producen los 4 productos. Entre los 53 dueños de fincas y productores de la fruta fresca, tienen en total aproximadamente una extensión de 62,9\% hectáreas cultivadas en estos productos, con una extensión máxima por finca de $12,5 \%$ hectáreas cultivadas y seguida por la extensión de 5,5 hectáreas como cantidad mínima de tierra

cultivada por productores de las frutas. Sin embargo 14 productores cuentan solo con 2 hectáreas representando un $27 \%$ del total de la muestra.

El $23 \%$ de los dueños de fincas producen café, $20 \%$ produce cacao, $8 \%$ pitahaya y $13 \%$ cítricos. Sin embargo, el $8 \%$ produce una combinación de café y cacao; el 14\%solo produce café, el $12 \%$ solo cacao y el $3 \%$ solo cítricos (ver Gráfico 1).

Gráfico 1. Número de productores por fruta cultivada

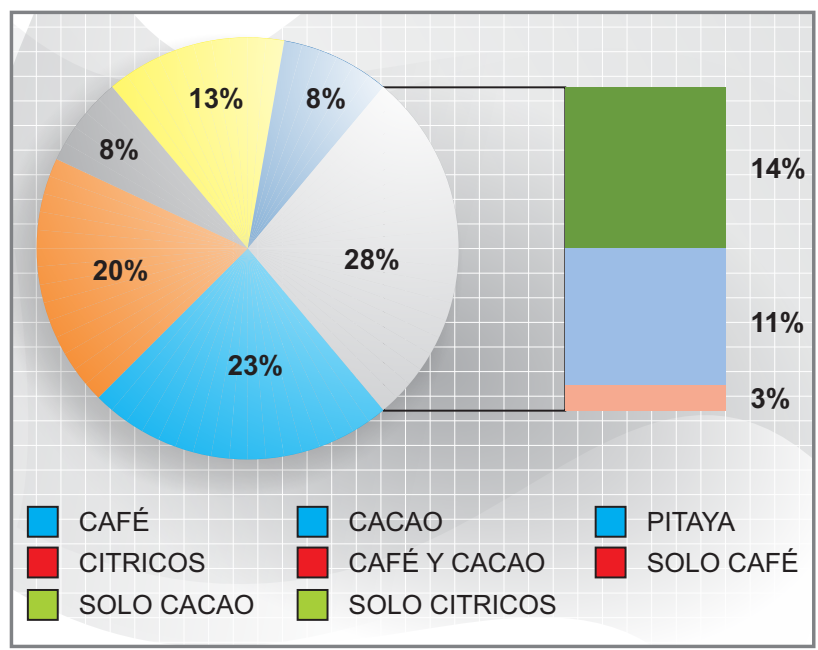

Fuente: La autora.

Asimismo, se evidencia que el $91 \%$ de los 53 productores de fruta fresca en Bucaramanga, no le da importancia a afiliarse a la Cámara de Comercio, puesto que su producción es vendida bien sea a la Federación que los representa según corresponda: de cafeteros, cacaoteros o Asopitayeros, o es de consumo interno, para lo cual no es necesario formalizar la unidad empresarial. (Ver Gráfico 2). 
Gráfico 2. Porcentaje de productores que registran sus unidades empresariales en cámara de Comercio ¿Registra en Cámara de Comercio?

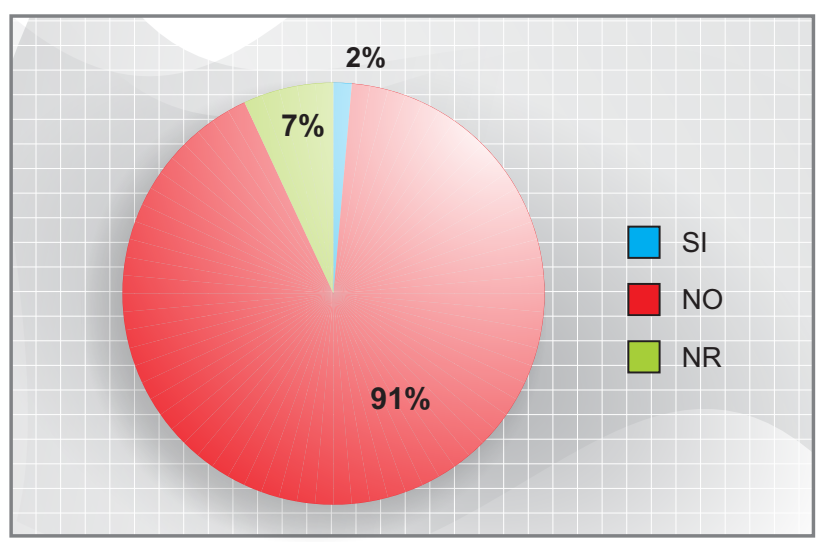

Fuente: La autora.

Por otro lado, el 62\% de los dueños de fincas que participaron en el Grupo Focal manifestaron no tener conocimiento de las Políticas de Gobierno del Orden Nacional, así como tampoco las de Orden Local para su sector, lo cual indica que no existe una comunicación efectiva entre los representantes del sector rural y el Gobierno en lo que refiere a estos productos, siendo solo el 32\% los que indican que si conocen de éstas Políticas y el 6\% decidieron no dar respuesta a ésta pregunta lo que muestra la indiferencia por parte de los productores frente a este tema.(ver Gráfico 3).

Gráfico 3. Porcentaje de agricultores que conocen las políticas de gobierno

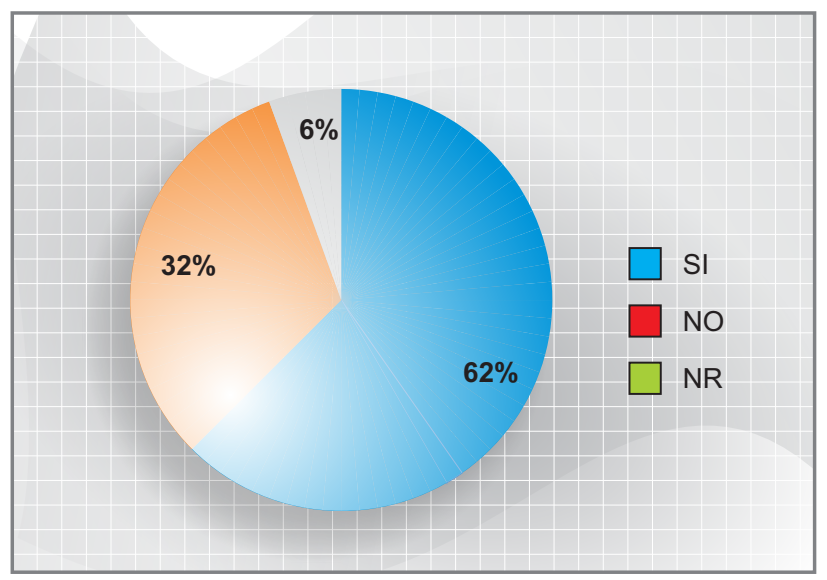

Fuente: La autora.
De igual forma, cuando se les pregunta sí reciben asistencia técnica y de qué entidad la reciben, el $41 \%$ de los productores encuestados se abstiene de responder, lo que puede considerarse como una inconformidad por parte de los agricultores frente a ésta temática, el 21\% afirma recibirla de Fedecafé, el 20\% recibe de la federación de cacaoteros, el $17 \%$ de la Unidad Municipal de Asistencia Técnica Agropecuaria (UMATA) como se ve en el gráfico 4.

Gráfico 4. Entidad de la que recibe

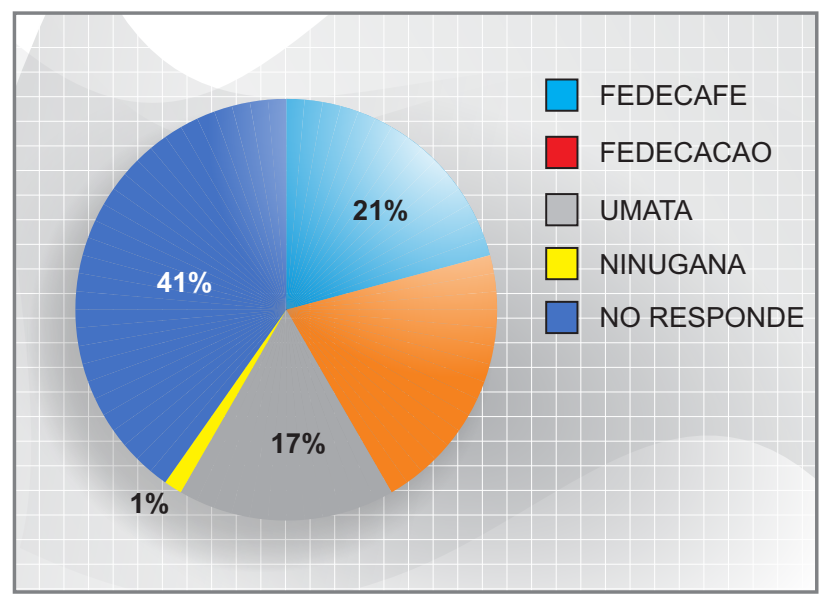

Fuente. La autora.

\section{Componente de Producción}

En el componente de producción se encontró que el $72 \%$ de los cultivadores / agricultores / dueños de fincas no tiene planes de producción, (Ver gráfico 5), $51 \%$ de los productores, evalúa y corrige errores de la producción o la cosecha anterior, (Ver gráfico 6). 
Análisis del perfil de las cadenas productivas del café, el cacao, la pitahaya y el limón Tahití, desde un enfoque de

Gráfico 5.Porcentaje de Agricultores que cuenta con planes de producción

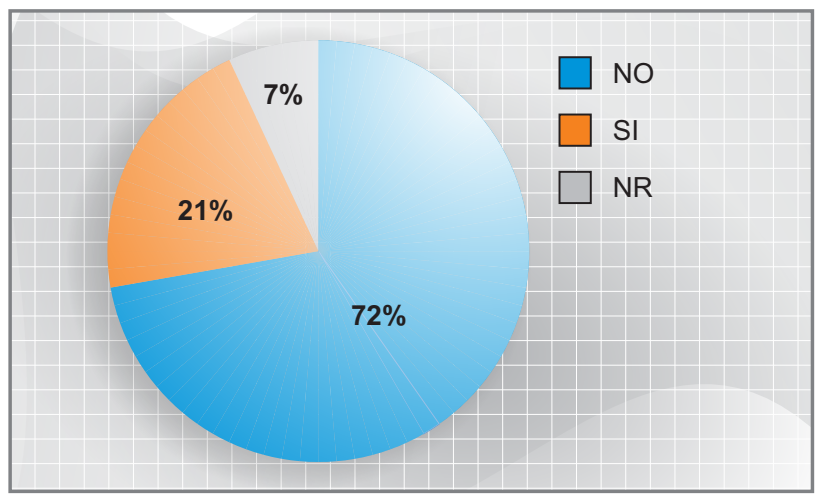

Fuente: La autora.

Gráfico 6. Porcentaje de Agricultores que evalúan y corrigen los errores detectado en la producción.

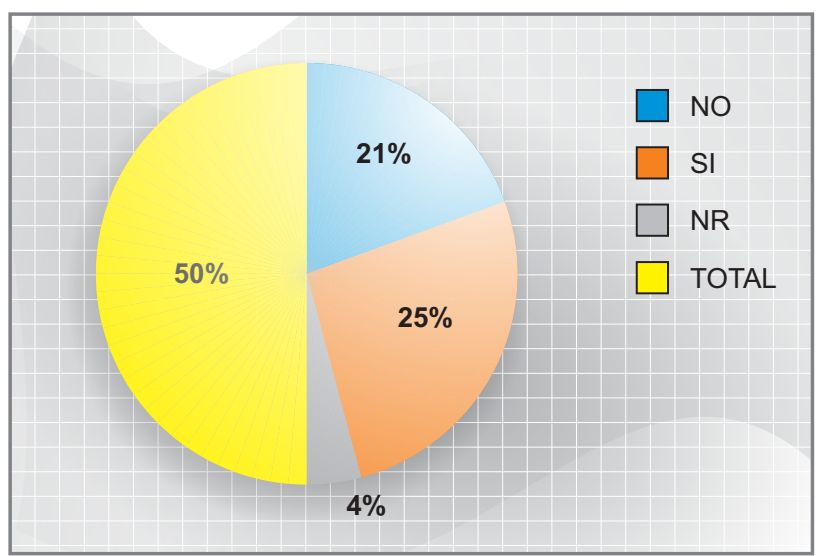

Fuente: La autora.

El $60 \%$ de los productores respondieron a la pregunta ¿Tienen una estrategia de ventas? Que no la tenían. (Ver gráfico 7), El 53 \% manifiesta tener asesorías técnicas para la producción (Ver gráfico 8) y el $36 \%$ afirma no tenerla por parte de ninguna entidad ni pública ni privada.
Gráfico 7. Porcentaje de Agricultores que tiene una estrategia de ventas o comercialización.

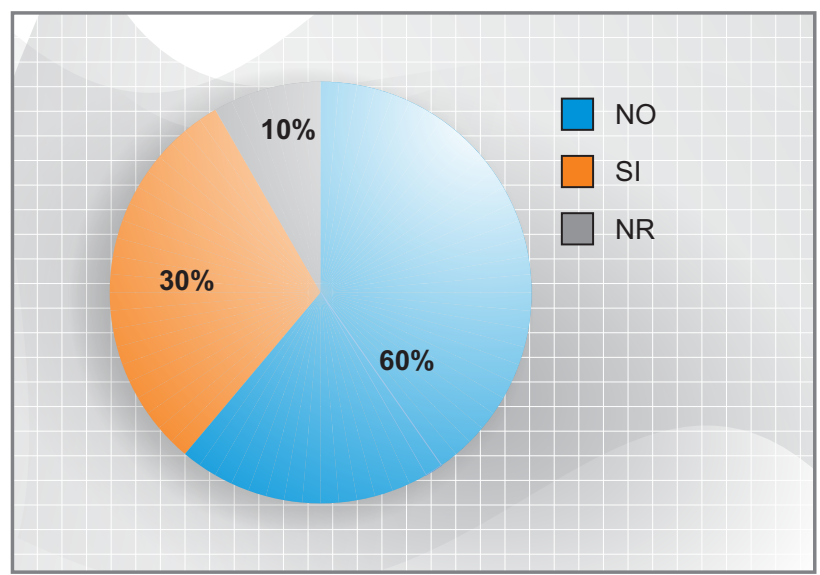

Fuente: La autora.

Gráfico 8. Porcentaje de Agricultores que evalúan sus fallas en la producción.

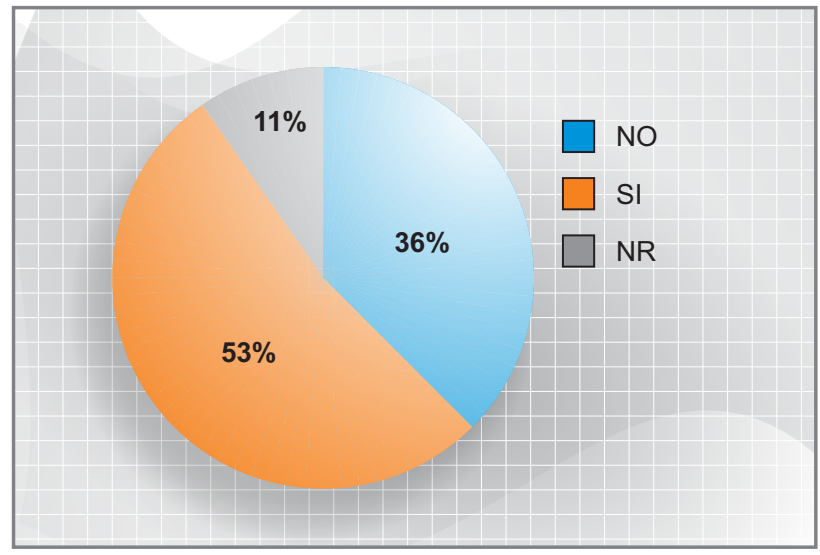

Fuente: La autora.

En cuanto a la variedad de los productos cultivados se encontró variedad en la producción de pitahaya amarilla y madura, cacao seco a granel. Por el lado de los cítricos está el limón, la mandarina y la naranja; y por el lado del café, la variedad del producto está en café seco tipo castilla y rojo. Igualmente los productores manifiestan que no solo producen fruta fresca del sector Citrícola, Café y cacao sino que también producen plátano, Maracuyá y moringa, lo que 
les ha permitido diversificar sus clientes y mantener un gran insumo para la recaudación de ingresos.

A su vez, en lo que refiere a los procesos de producción para cada uno de los productos de los sectores de café, cacao, Pitahaya y cítricos del municipio de Bucaramanga, se pudo evidenciar en el cuestionario que primero realizan la preparación de la tierra, se hace la recolección de semillas, siembra, fertilización, limpia, abono, recolección, despulpar, secado cuando es necesario y finalmente se realiza la respectiva comercialización para llegar al consumidor final.

\section{Componente de internacionalización}

Respecto a la internacionalización de los productos de frutas frescas del municipio de Bucaramanga y específicamente del Cacao, Café, Cítricos y Pitahaya, se encontró que el $87 \%$ de los productores de estas frutas que participaron en el grupo focal afirma que no ha realizado procesos de exportación, ( Ver gráfico 9); el $61 \%$ afirma que desconoce los beneficios de realizar un proceso de expansión comercial a mercados internacionales.( Ver gráfico 10).

Gráfico 9. Porcentaje de Agricultores que han realizado procesos de exportación

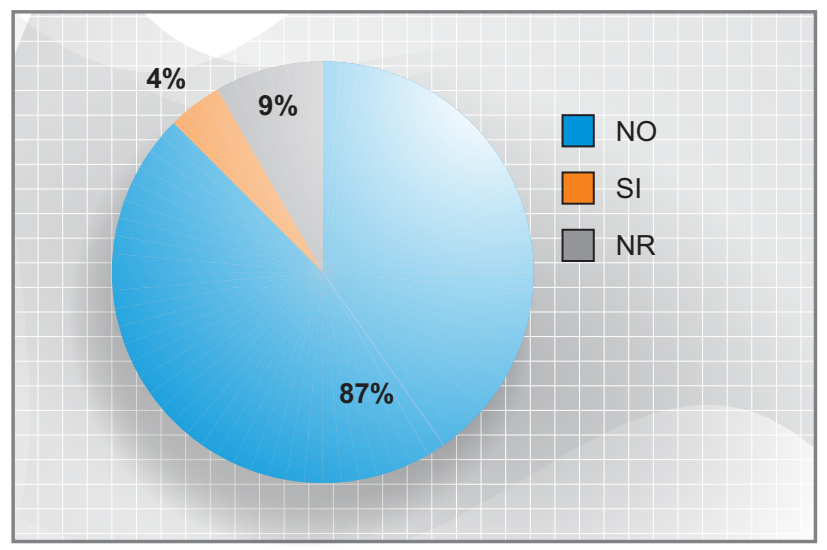

Fuente: La autora.
Gráfico 10. Porcentaje de Agricultores que conoce los beneficios de exportar.

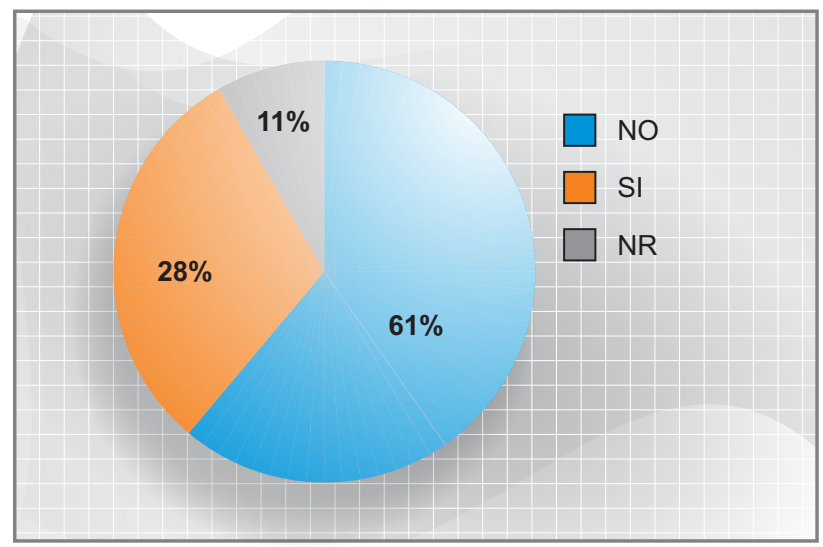

Fuente: La autora.

Un 77\% de los encuestados dijeron no conocer sobre los procedimientos $\mathrm{y} / \mathrm{o}$ requisitos para exportar y tipos de transporte para la exportación de sus productos cultivados. El $53 \%$ afirman tener interés en exportar, de los cuales el $15 \%$ manifiesta que le interesaría exportar a países de Europa, el 4\% a Estados Unidos, 2\% a Canadá y el $77 \%$ de los Agricultores que participaron en el grupo focal no responde a la pregunta: ¿A qué lugar desearía exportar? , lo que se debe probablemente a que los dueños de fincas y/o productores no conocen los beneficios de exportar. (Grafico 11).

Gráfico 11. Porcentaje de Agricultores por destino país de exportación.

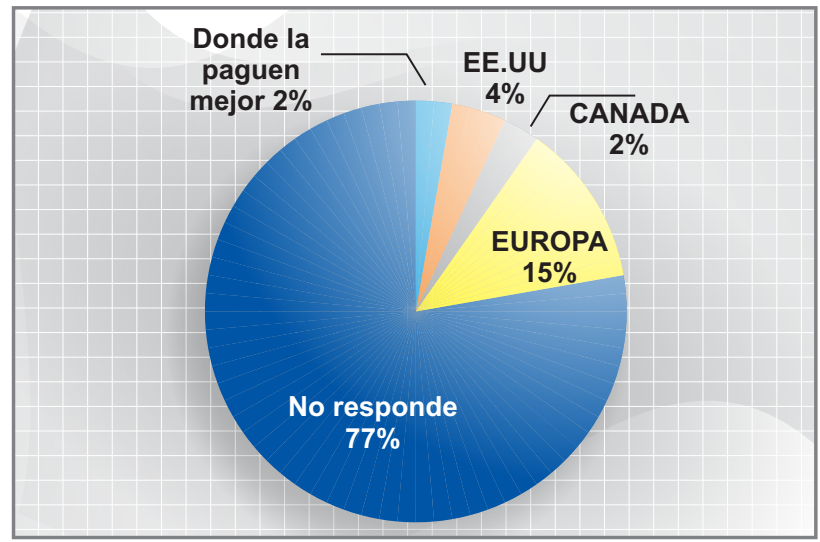

Fuente: La autora. 
Análisis del perfil de las cadenas productivas del café, el cacao, la pitahaya y el limón Tahití, desde un enfoque de

internacionalización, innovación y responsabilidad social empresarial en Bucaramanga

El $81 \%$ de los productores encuestados manifiesta no importar insumos para la producción de las frutas frescas y granos (Pitahaya, Cítricos, Café y Cacao), un $4 \%$ sí importa insumos y el $15 \%$ no responde a la pregunta ¿Importa algún insumo para realizar la producción de sus cultivos?.

E1 $62 \%$ de los productores no tiene conocimiento de lo que desean de sus productos los consumidores y el $74 \%$ manifiestan que todos los productores de los corregimientos de Bucaramanga cosechan la misma calidad del producto por lo que no existen diferencias entre ninguno de los productos ofertados por los agricultores.

Los resultados descritos en párrafos anteriores permiten identificar que los productores del sector agrícola en Bucaramanga en lo referente a café, cacao, pitahaya y cítricos no han realizado estudio de mercados que permitan proyectar sus unidades empresariales hacia los mercados externos de forma directa sino que estos procesos debilidad en lo que refiere a los procesos de innovación, puesto que el $60 \%$ de los participantes del Grupo Focal informan no conocer herramientas que les permitan implementar procesos que diferencien sus productos de los demás productores, lo que refleja el desconocimiento en cuanto a los aspectos de nuevas tecnologías (maquinarias con tecnología moderna, software, entre otros) aplicados al sector agropecuario para llegar ser más productivo y a su vez competitivo.

El $83 \%$ no ha adquirido nuevas maquinarias en los últimos dos años y por tanto el $87 \%$ no ha realizado capacitaciones a su personal para el uso de nuevas maquinarias y/o herramientas adquiridas, el 77\% no tienen un Plan de Negocios el cual sería una herramienta básica para posicionarse en el mercado analizando sus competidores, la demanda, los comportamientos de precios entre otros temas.(Ver gráfico12).

Gráfico 12. Porcentaje de Agricultores que han adquirido nuevas máquinas en los últimos dos años.

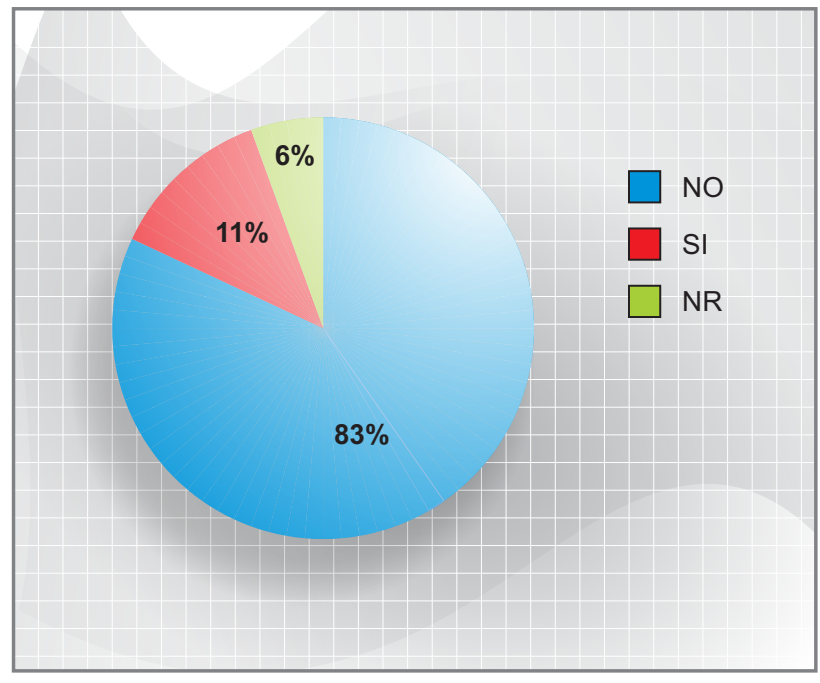

Fuente: La autora.
La investigación realizada permitió

identificar que existe un alto porcentaje de
En el caso del sector Citrícola en Bucaramanga aún no existe una entidad que represente a los productores de las frutas del sector, por lo cual requieren de un mayor acompañamiento de parte del gobierno y de las universidades.

\section{Componente de Innovación}


El 55\% no está asociado a ninguna entidad que pueda fortalecer sus procesos de manera más eficiente, el $85 \%$ no utiliza herramientas tecnológicas para llevar la contabilidad, ventas y cantidades de producción, lo que permite evidenciar que la producción y comercialización de los productos del sector agrario se realizan de forma rudimentaria y el 75\% no invierten en investigación y desarrollo para mejorar sus procesos, de producción, comercialización y exportación, implementar estrategias de distribución y logística. (Ver gráfico 13).

Gráfico 13. Porcentaje de Agricultores que invierten en Investigación y Desarrollo

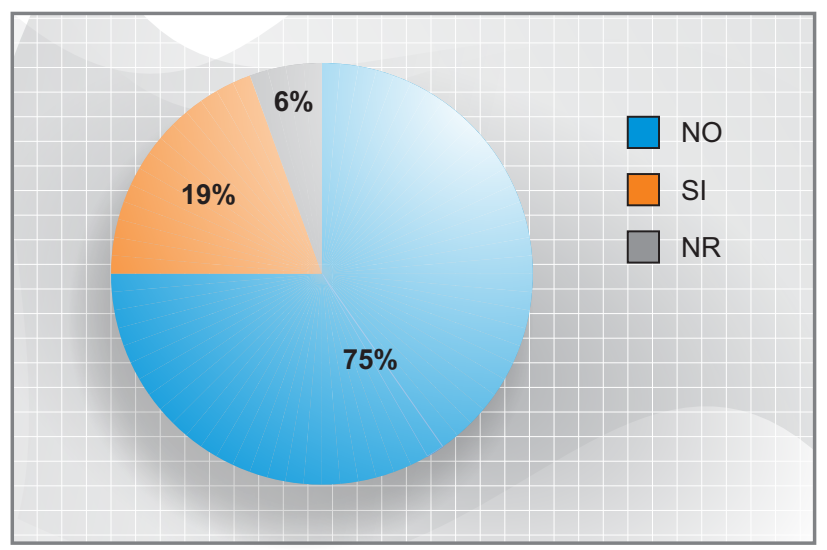

Fuente: La autora.

Por lo tanto, es importante generar estrategias que permitan concientizar y mejorar los procesos de innovación en el sector Agropecuario, puesto que la innovación permite ser más productivo, generar productos de mayor calidad y mejores oportunidades para la internacionalización fortaleciendo la competitividad del sector y la economía regional.

\section{Componente de responsabilidad social empresarial}

La Responsabilidad Social Empresarial ha cobrado importancia en los últimos años para los empresarios por considerarse una manera diferente de hacer crecer sus empresas no solo en lo monetario sino en lo social generando ventajas competitivas en el entorno de los negocios y que por tanto beneficiará de forma directa a los empleados de las unidades empresariales y la economía de un ente territorial.

Por tanto, es importante incluir en la planeación estratégica del sector agropecuario planes y programas de Responsabilidad Social, sin embargo, al revisar los resultados de la investigación realizada a las cadenas productivas del café, cacao, Pitahaya y Cítricos del municipio de Bucaramanga se evidencia según los cálculos estadísticos realizados que el $66 \%$ de los productores de éstas frutas frescas( naranja, limón, pitahaya) y granos ( café y cacao) desconocen los diferentes programas de Responsabilidad Social Empresarial que podrían implementar en sus unidades empresariales, además de no familiarizarse fácilmente con el concepto de RSE (ver Gráfico 14).

Gráfico 14 Porcentaje de Agricultores que conocen sobre Responsabilidad Social Empresarial.

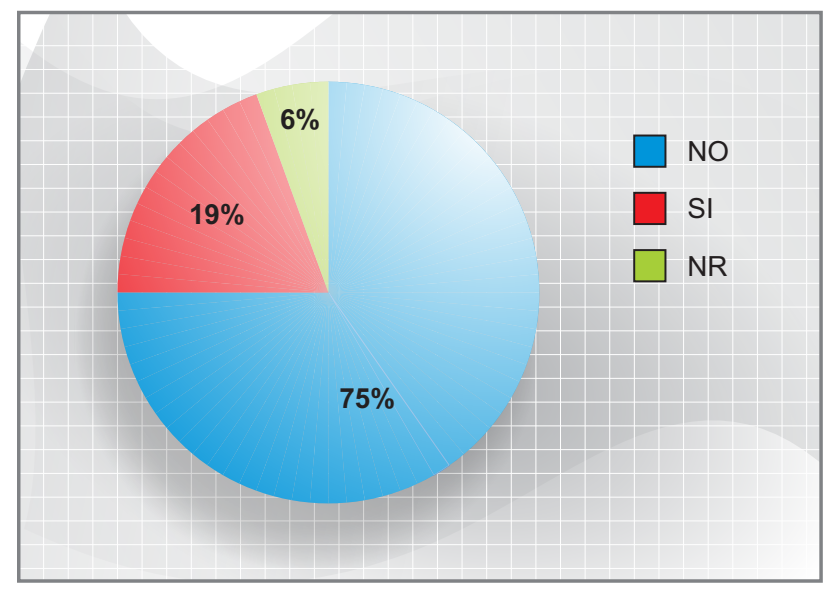

Fuente: La autora. 
El $75 \%$ de los productores encuestados no aplica ningún tipo de estrategias relacionadas con la RSE, el $74 \%$ no invierte en el desarrollo de las capacidades de sus empleados, El $70 \%$ informó no tener un plan de prevención de riesgos ambientales y sociales; sin embargo el $62 \%$ dijo sí invertir en el cuidado del medio ambiente.

\section{Conclusiones y discusión}

De acuerdo al proceso de investigación que se realizó a las cadenas productivas de café, cacao, Pitahaya y Cítricos del municipio de Bucaramanga se concluyó que es necesario que el Estado, las entidades que representan a los diferentes agricultores e incluso las universidades planteen estrategias de prevención e intervención al sector agrario del municipio que permitan fortalecer o crear ventajas competitivas que generen diferenciadores para el posicionamiento del sector cítrico, cafetero, cacaotero y pitahayero en el mercado internacional y doméstico, mediante la inclusión de procesos de innovación y responsabilidad social empresarial, planificación, tecnificación de la producción, estrategias de comercialización, logística $\mathrm{y}$ distribución de los productos correspondientes a los sectores objeto del presente estudio, con el fin de generar nuevas posibilidades para la economía regional, a partir de productos cultivados en el ente territorial, beneficiando a los agricultores y sus familias en primera instancia, generando nuevas oportunidades de empleo y fuentes de ingresos que mejoren su calidad de vida $\mathrm{y}$ proporcionar productos para el consumo de calidad.

Por tanto, se sugiere como producto de ésta investigación la realización de un plan que tenga como mínimo 4 estrategias: 1. Educación al sector. 2. Fortalecimiento para la comunicación asertiva.3. Asesoría para fortalecer la elaboración y puesta en práctica de planes de producción, comercialización, exportación y Responsabilidad Social Empresarial. 4. Tecnificación de Cultivos, ( Ver Tabla 2).

Tabla 2 Estrategias para fortalecer la competitividad desde el enfoque de innovación, internacionalización y responsabilidad social empresarial.

\begin{tabular}{ll}
\hline ESTRATEGIA & \multicolumn{1}{c}{ ACTIVIDAD } \\
\hline EDUCACIÓN AL SECTOR & $\begin{array}{l}\text { Planeación Estratégica y presentación de productos } \\
\text { (Marketing) con el fin de variar la presentación de nuestros } \\
\text { productos con enfoques diferenciadores que hagan más } \\
\text { competitivo el producto. }\end{array}$ \\
& $\begin{array}{l}\text { Aspectos generales y normatividad de la Responsabilidad } \\
\text { Social Empresarial. }\end{array}$ \\
& $\begin{array}{l}\text { Procesos de exportación, Logística para la comercialización } \\
\text { domestica e internacional, y Normas de exportación. } \\
\text { Elaboración de un Plan exportador. }\end{array}$
\end{tabular}


COMUNICACIÓN ASERTIVA

\author{
ASESORÍAS Y \\ FORTALECIMIENTO PARA LA \\ ELABORACIÓN DE:
}

TECNIFICACIÓN DE CULTIVOS
Experiencias de tecnologías aplicadas para mejorar los procesos de producción y tecnificación de los productos finales.( diversificación del producto).

Informar las Políticas de Gobierno, proyectos que tenga el Gobierno Nacional, Departamental y Local frente a los aspectos que permitan el desarrollo de sus productos y el mejoramiento de la calidad de vida.

Uso de herramientas básicas tecnológicas (Excel, Word) que permita consignar las ventas, producción, salarios que devengan los empleados entre otros temas administrativos.

Generar espacios de comunicación permanente entre academia, Gobierno Local y Departamental, Federaciones y/o representantes de las Asociaciones, y productores del sector rural, para identificar necesidades y estrategias que requiere el sector, así como socializar los proyectos en beneficio del sector.

Plan de Producción.

Plan de Comercialización.

Generar Estrategia de Responsabilidad Social Empresarial.

Desarrollar un Plan exportador.

Renovación de cultivos para mantenerlos más jóvenes y que puedan resistir los cambios climáticos con mayor fortaleza, garantizando a los productores la producción de su cultivo y la calidad del mismo.

Dotar de maquinarias acordes con la tecnología requerida para la producción y transformación del producto.

Fuente: La autora. 


\section{Referencias}

Agronet. Agrocadenas . (1992-2013). Recuperado el 25 de Mayo de 2015, de Comparativo en la producción de Pitahaya por departamentos:

http://www.agronet.gov.co/www/htm3b/Report esAjax/VerReporte.aspx.

Aguilar P, Escobar J, pássaro P.(2012).Situación Actual de Cítricos en Colombia: limitantes y perspectivas. Corporación Universitaria La Sallista. Serie La Sallista Investigación y Ciencia.

Delgado A. (2010).Tesis. Análisis General de mercado de la Pitahaya Amarilla (selenicereus megalanthus), con fines de su comercialización en la república popular China (RPC).Universidad Autónoma de Occidente. Facultad de Ciencia Económicas y Administrativas. Cali. Recuperado en línea. http://bdigital.uao.edu.co/bitstream/10614/1457 /1/TMD00599.pdf.

Espinal, G. (marzo de 2005). Ministerio de agricultura y desarrollo rural observatorio agro cadenas Colombia, la cadena de cacao en C o 1 o m b i a. O b t e n i d o d e http://www.agronet.gov.co/www/docs_agronet/ 2005112145659_caracterizacion_cacao.pdf.

Espinal G.(2005)Ministerio de Agricultura y Desarrollo Rural .Observatorio Agrocadenas Colombia. Trabajo $N^{\circ}$ 66.La cadena Citricos en Colombia.Una mirada Global de su estructura y dinamica 1992-2005.Bogotá. Recuoerado en linea.link:

http://bibliotecadigital.agronet.gov.co/jspui/bits tream/11348/6323/1/2005112155430_caracteriz acion_citricos.pdf

FAO. Fiat Panis. (2012). Swisscontact. Análisis de la cadena de valor del café con enfoque de seguridad alimentaria y nutricional. Nicaragua.

F e d e r a c i ó $n \quad N$ a c i o n a 1 de Cafeteros.(2013).Comportamiento de la Industria Cafetera Colombiana 2013. https://www.federaciondecafeteros.org/static/fil es/Informe_Industrial_2013_Web.pdf.

Instituto Colombiano Agropecuario. ICA. (2010). Pitahaya Colombiana podría llegar a Corea. Recuperado en Linea. http:/www.ica.gov.co/Noticias/Agricola/2010/ Pitahaya-colombiana-podria-1legar-aCorea.aspx.

López, A., Contreras, R., \& Molina, R. (Juliodiciembre de 2011). La responsabilidad Social Empresarial como estrategia de Competitividad en el sector Alimentario. Cuadernos de Administración, 24(43), 261-683.

Márquez, J. (1998). Economía y política regional en ESPAÑA ante la Europa del siglo XXI. Competitividad e Internacionalización. Madrid, España: Akal S.A.

Ministerio de Agricultura y Desarrollo rural, Observatorio Agrocadenas Colombia.(2005).La Cadena del Café en Colombia una mirada global de la estructura y dinámica 1991-2005. Bogotá.

Ministerio de Agricultura y Desarrollo Rural, Gobernación de Santander, Fondo Nacional de 
Fomento Hortofrutícola, Asohofrucol \&Sociedad de Agricultores y Ganaderos del Valle, (2006),Plan Frutícola Nacional. Desarrollo de la Fruticultura de Santander. Bucaramanga. link:

http://www.asohofrucol.com.co/archivos/bibliot eca/biblioteca_114_Plan\%20Na1\%20frursantander.pdf

Mojica A, Paredes Joaquín. ( 2006).Ensayos sobre Economía Regional. Centro regional de Estudios Económicos Bucaramanga. Características del Cultivo del Cacao en Santander. Banco de la republica. Bucaramanga.

Moncayo, E. (2004). Nuevos enfoques del desarrolo territoriall: Colombia en una perspectiva latinoamericana. Colombia: Universidad nacional de Colombia. Programa de Naciones Unidas Y Cepal.

Ortega Cárdenas, Alfonso. (2007). Economía Colombiana. Banco de la Republica. Biblioteca Luis Ángel Arango. 3 era edición. Bogotá.
PNUD, DPS. (s.f.). Perfil Ocupacional y generación de ingresos en el Departamento de Quindío. Contexto Regional. Rodríguez, Combeller Carlos. El nuevo escenario la cultura de calidad y productividad en las empresas.:

Revista Modelo. Portafolio. (2013) Sembramos a Colombia por el mundo. Colombia Brilla con Pitahaya Amarilla. Recuperado en el link.

http://www.cci.org.co/ccinew/pdf/SEMBREM OS/JULIO\%202010\%20REVISTA\%2013/mod elo.pdf

Rueda, N. (2003). Paradojas de un ordenamiento urbano. Bucaramanga, Colombia: Universidad Santo Tomás, deccional Bucaramanga. ISBN 978-958-96113-9-7. 